Article

\title{
Applications of Lactobacillus acidophilus-Fermented Mango Protected Clostridioides difficile Infection and Developed as an Innovative Probiotic Jam
}

\author{
Bao-Hong Lee ${ }^{1}$, Wei-Hsuan Hsu ${ }^{2,3}{ }^{\mathbb{D}}$, Hao-Yuan Chien ${ }^{1} \mathbb{D}$, Chih-Yao Hou ${ }^{4}$, Ya-Ting Hsu ${ }^{2}$, You-Zuo Chen ${ }^{2}$ \\ and She-Ching $\mathrm{Wu}^{5, *}$
}

1 Department of Horticulture, National Chiayi University, Chiayi 600355, Taiwan; bhlee@mail.ncyu.edu.tw (B.-H.L.); s1072093@mail.ncyu.edu.tw (H.-Y.C.)

2 Department of Food Safety/Hygiene and Risk Management, College of Medicine, National Cheng Kung University, Tainan 701401, Taiwan; whhsu@mail.ncku.edu.tw (W.-H.H.); sc6094017@gs.ncku.edu.tw (Y.-T.H.); xzp666842@gmail.com (Y.-Z.C.)

3 Center of Allergy and Mucosal Immunity Advancement at the National Cheng Kung University, Tainan 701401, Taiwan

4 Department of Seafood Science, National Kaohsiung University of Science and Technology, Kaohsiung 81157, Taiwan; chihyaohou@gmail.com

5 Department of Food Science, National Chiayi University, No. 300 Syuefu Rd., Chiayi 600355, Taiwan

* Correspondence: scwu@mail.ncyu.edu.tw; Tel.: +886-05-2717622

check for

updates

Citation: Lee, B.-H.; Hsu, W.-H.; Chien, H.-Y.; Hou, C.-Y.; Hsu, Y.-T.; Chen, Y.-Z.; Wu, S.-C. Applications of Lactobacillus acidophilus-Fermented Mango Protected Clostridioides difficile Infection and Developed as an Innovative Probiotic Jam. Foods 2021, 10, 1631. https://doi.org/10.3390/ foods10071631

Academic Editor: Yiannis Kourkoutas

Received: 31 May 2021

Accepted: 8 July 2021

Published: 14 July 2021

Publisher's Note: MDPI stays neutral with regard to jurisdictional claims in published maps and institutional affiliations.

Copyright: (c) 2021 by the authors. Licensee MDPI, Basel, Switzerland. This article is an open access article distributed under the terms and conditions of the Creative Commons Attribution (CC BY) license (https:// creativecommons.org/licenses/by/ $4.0 /)$.
Abstract: Clostridioides difficile infection (CDI) is a large intestine disease caused by toxins produced by the spore-forming bacterium C. difficile, which belongs to Gram-positive bacillus. Using antibiotics treatment disturbances in the gut microbiota and toxins produced by $C$. difficile disrupt the intestinal barrier. Some evidence indicates fecal microbiota transplantation and probiotics may decrease the risk of CDI recurrence. This study aimed to evaluate the efficacy of fermented mango by using the lactic acid bacteria Lactobacillus acidophilus and develop innovative products in the form of fermented mango jam. L. acidophilus-fermented mango products inhibited the growth of $C$. difficile while promoting the growth of next-generation probiotic Faecalibacterium prausnitzii. Both supernatant and precipitate of mango-fermented products prevented cell death in gut enterocyte-like Caco-2 cells against $C$. difficile infection. Mango-fermented products also protected gut barrier function by elevating the expression of tight junction proteins. Moreover, L. acidophilus-fermented mango jam with high hydrostatic pressure treatment had favorable textural characteristics and sensory quality.

Keywords: jam; Lactobacillus acidophilus; Clostridioides difficile; mango; Faecalibacterium prausnitzii

\section{Introduction}

The incidence of Clostridioides difficile (formerly Clostridium difficile) infection (CDI) is 10-fold higher in older adults than in young adults [1]. A clinical study found that the abundance of several next-generation probiotics, including Akkermansia muciniphila, Escherichia coli, and Klebsiella spp., was higher in patients with CDI than in controls, suggesting these bacterial populations may be involved in CDI development [2]. However, a reduction in the number of butyrate-producing bacteria, such as Lachnospira spp., Butyricimonas spp., and Faecalibacterium prausnitzii, was found in patients with CDI $[3,4]$. Bacterium F. prausnitzii is Gram-positive, nonspore-forming, and nonmotile [5]. F. prausnitzii represents about 5\% of the total population of intestinal bacteria, which is one of the most abundant species in the gut microbiota of healthy adults and is the predominant butyrate-producing bacterium in the gastrointestinal tract. The D-lactate and butyrate ( $>10 \mathrm{mM}$ butyrate) were major end products of F. prausnitzii during glucose fermentation [6,7]. F. prausnitzii contributes to the establishment of epithelial homeostasis, which modulates colonic goblet cells and gut barrier function [8]. Moreover, F. prausnitzii and its cultural supernatant alleviate intestinal 
inflammation in the colitis mice model by reducing intestinal permeability [9]. The mechanism underlying the protective effects of $F$. prausnitzii mediated by elevating tight junction proteins [10]. A monolayer of epithelial cells forms an interface between the host and the microbiota that colonizes the gastrointestinal tract. Commensal gut microbiota and their metabolites interact with epithelial cells in the intestine of humans. A study reported that F. prausnitzii-derived extracellular vesicles have the potential for promoting activation of Toll-like receptors and intestinal immunity [11], these indicate that F. prausnitzii is essential to health of hosts. There is increasing evidence that metabolites from F. prausnitzii regulate the intestinal epithelium. Medium supplemented with flavin and cysteine or glutathione has been shown to support the growth of F. prausnitzii [12]. In addition, F. prausnitzii uses mucin (MUC) as its sole energy source and is considered one of the "next-generation probiotics."

Numerous lactic acid bacteria and yeasts have been reported to use mango as nutrients thereby producing postbiotics [13-17]. Studies have demonstrated that the polyphenolic compounds of mango peel and mangiferin conversion were increased through gastrointestinal digestion and gut microbiota fermentation $[18,19]$. Moreover, mango peel aids in the regulation of gut microbiota, including an increase in the abundance of Faecalibacterium, Bifidobacterium, Roseburia, Eubacterium, Catenibacterium, Prevotella, Phascolarctobacterium, Collinsella, and Bacteroides genera [20].

MUC expression has been usually determined during the growth and differentiation of the enterocyte-like Caco-2 and goblet cell-like LS174T cells. Caco-2 (expressing MUC-1, MUC-3, MUC-4, MUC-5A/C, and MUC-13) and LS174T (expressing MUC-1, MUC-2, and MUC-6) cell lines have been discovered great in vitro models for research the specific mechanisms responsible for expressing mucin [21]. It has been reported that oligosaccharides including stachyose, cellobiose, raffinose, lactulose, and chitooligosaccharides can affect the adhesion of F. prausnitzii to mucus-secreting intestinal epithelial cells [22]. Therefore, we investigated the effects of Lactobacillus acidophilus BCRC14079-fermented mango on the growth of F. prausnitzii and the protection of Caco-2 cells for the intestinal biological role in human health. Finally, the preparation conditions of L. acidophilus BCRC14079-fermented mango jam was investigated.

\section{Materials and Methods}

\subsection{Chemicals}

Fetal bovine serum (FBS) was purchased from Life Technologies (Auckland, New Zealand). Dimethyl sulfoxide (DMSO) was obtained from Wako Pure Chemical Industries (Saitama, Japan). Triton X-100, trypsin, and sodium dodecyl sulfate (SDS) were purchased from Sigma Chemical Co. (St Louis, MO, USA). Dulbecco's modified Eagle's medium (DMEM), streptomycin, and penicillin were purchased from HyClone Laboratories (Logan, UT, USA). Lactobacilli MRS broth was purchased from Difco Laboratories (Detroit, MI, USA). BHI medium was obtained from Thermo Fisher Scientific (Waltham, MA, USA).

\subsection{Fermentation}

The pulp of mango fruit was homogenized into a puree using a homogenizer, freezedried to a powder, and stored at $-80^{\circ} \mathrm{C}$. The mango powder was formulated $(30 \%)$ as a culture medium and fermented with L. acidophilus (BCRC14079; Food Industry Research and Development Institute, Hsin Chu, Taiwan) for 1,3, and $5 \mathrm{~d}$. The bacterial counts, $\mathrm{pH}$ level, and titratable acidity were determined on days 1,3 , and 5 . $\mathrm{pH}$ value was detected by a digital pH meter (OHAUS Corporation, Parsippany, NJ, USA) that calibrated with $\mathrm{pH} 4.0$ and 7.0 buffers. In titratable acids measurements, $5 \mathrm{~mL}$ of the tested sample was used and titrated by $0.1 \mathrm{~N}$ sodium hydroxide $(\mathrm{NaOH})$ to $\mathrm{pH} 8.2$.

L. acidophilus BCRC14079 was cultured in MRS broth under anaerobic conditions at $37^{\circ} \mathrm{C}$ by using an atmosphere generation system (Oxoid, Basingstoke, UK). The number of the lactobacilli was detected on MRS agar plates under anaerobic cultivation. 
The fermented products were centrifuged and divided into the L. acidophilus BCRC14079fermented mango supernatant and L. acidophilus BCRC14079-fermented mango precipitate. Water extracts of unfermented mango were used as controls. L. acidophilus BCRC14079fermented mango supernatant was filtered through a $0.22 \mu \mathrm{m}$ filter. L. acidophilus BCRC14079fermented mango precipitate contained the biomass of bacteria. Therefore, it was extracted with $100{ }^{\circ} \mathrm{C}$ water for $1 \mathrm{~h}$ and the solution was then filtered through a $0.22 \mu \mathrm{m}$ filter. Finally, these products (L. acidophilus BCRC14079-fermented mango supernatant and L. acidophilus BCRC14079-fermented mango precipitate-water extract) were freeze-dried and then stored at $-80{ }^{\circ} \mathrm{C}$ until use in the intestinal cell and microbial experiments.

\subsection{Cell Culture}

Cell culture and treatment Caco-2 cell line was purchased from the Bioresource Collection and Research Center (BCRC, Food Industry Research and Development Institute, Hsin Chu, Taiwan). Cells were grown in a DMEM medium that contained $10 \%$ heat-inactivated FBS, $2 \mathrm{mM}$ of L-glutamine, and $2 \mathrm{mM}$ of glutamine in a humidified atmosphere of $95 \%$ air and $5 \% \mathrm{CO}_{2}$ under $37^{\circ} \mathrm{C}$ cultivation.

\subsection{Western Blotting}

An ice-cold buffer containing 1\% of Triton X-100, 0.1\% of SDS, $500 \mathrm{mM}$ of sodium vanadate, $20 \mathrm{mM}$ of Tris- $\mathrm{HCl}$ (pH 7.4), $10 \mathrm{mM}$ of NaF, $2 \mathrm{mM}$ of EDTA, $1 \mathrm{mM}$ of phenylmethanesulfonyl fluoride, and $10 \mathrm{mg} / \mathrm{mL}$ of aprotinin was used to lyse the cells. The supernatant of cells was obtained from centrifuged $(12,000 \times g, 10 \mathrm{~min})$ cell lysate. SDSPAGE $(10 \%)$ was used to resolve the proteins and transferred them to a polyvinylidene fluoride membrane. Nonfat milk (5\%) was used to block membranes for $1 \mathrm{~h}$, and then primary antibodies were added to membranes for 2-4 h. Subsequently, the membrane was washed with phosphate-buffered saline with Tween-20 (PBST) for 5 min three times and incubated with horseradish peroxidase (HRP)-linked secondary antibody for $1 \mathrm{~h}$. After washing three times with PBST, the enhanced chemiluminescent reagent (Millipore, Billerica, MA, USA) was used to determine the protein concentration.

\subsection{L. acidophilus BCRC14079-Fermented Mango Inhibited C. difficile Growth}

The $C$. difficile 630 strain (ATCC ${ }^{\circledR \circledR}$ BAA-1382 ${ }^{\mathrm{TM}}$ ) was anaerobically cultured in brain heart infusion (BHI) medium with $0.05 \%$ L-cysteine for $16 \mathrm{~h}$ at $37^{\circ} \mathrm{C}$ and then refreshed the broth until grown to early stationary phase $\left(\mathrm{OD}_{600} \approx 0.7\right)$. Subsequently, $C$. difficile culture $\left(1 \times 10^{6} \mathrm{CFU} / \mathrm{mL}\right)$ was added into fresh BHI broth containing 31.25, 62.5, 125, 250, and $500 \mu \mathrm{g} / \mathrm{mL}$ L. acidophilus BCRC14079-fermented mango samples. Three independent samples were analyzed for each experiment. $\mathrm{OD}_{600}$ was measured after culturing the cells for different times.

\subsection{C. difficile Infection in Caco-2 Cells}

Caco-2 cells were incubated with DMEM medium without antibiotics and FBS before being infected. After overnight incubation, a pellet of $C$. difficile was collected and resuspended in anaerobic presterilized DMEM. The bacterial suspension was used to infect Caco-2 cells with the infected ratio of 100:1 (bacteria:cell) anaerobically for 30-180 min. Cell viability was determined by using the reduced mitochondrial activity (MTT) assay according to the manual (Sigma-Aldrich Chemical Co., St Louis, MO, USA).

\subsection{Investigation of L. acidophilus BCRC14079-Fermented Mango Regulated Growth of F. prausnitzii}

F. prausnitzii (BCRC81047) was obtained from Food Industry Research and Development Institute, Hsin Chu, Taiwan, which was cultured in YCFA medium in anaerobic condition for $24 \mathrm{~h}$ at $37^{\circ} \mathrm{C}$ (YCFA medium is formulated according to American Type Culture Collection recommendations). After overnight incubation, bacterial pellets were then refreshed in YCFA broth until to grow to early stationary phase $\left(\mathrm{OD}_{600} \approx 0.8\right)$. Sub- 
sequently, fresh F. prausnitzii $\left(1 \times 10^{6} \mathrm{CFU} / \mathrm{mL}\right)$ was then added to YCFA broth, which contained 125,250 , and $500 \mu \mathrm{g} / \mathrm{mL}$ of samples. Triplicate repeats were analyzed for each experiment. $\mathrm{OD}_{600}$ was measured after culturing the cells for different times.

\subsection{Assay for Short-Chain Fatty Acids (SCFAs)}

The bacteria cultural solution was collected and centrifuged at $13,000 \times \mathrm{g}$ and $4{ }^{\circ} \mathrm{C}$ for $15 \mathrm{~min}$ to obtain the supernatant for subsequent analysis. The levels of SCFAs such as acetic acid, propionic acid, and butyric acid were performed by gas chromatographyflame ionization detection (GC-FID) that used the Shimadzu GC-2010 (Shimadzu Corp, Tokyo, Japan) with a capillary column (BP21 FFAP $30 \mathrm{~m} \times 0.53 \mathrm{~mm}$ i.d., $0.50 \mu \mathrm{m}$ film thickness, Trajan, Melbourne, Australia). The carrier gas was nitrogen, and the splitless injection volume was $1 \mu \mathrm{L}$. Auxiliary gases for the flame ionization detector were hydrogen ( $30 \mathrm{~mL} / \mathrm{min}$ of flow rate) and dry air $(300 \mathrm{~mL} / \mathrm{min}$ of flow rate). The temperatures of the injector and detector were $220^{\circ} \mathrm{C}$ and $240{ }^{\circ} \mathrm{C}$, respectively. The temperature of the GC oven was first set at $90{ }^{\circ} \mathrm{C}$ for $1 \mathrm{~min}$ and elevated to $150{ }^{\circ} \mathrm{C}$ at $10^{\circ} \mathrm{C} / \mathrm{min}$, and then to $200{ }^{\circ} \mathrm{C}$ at $20^{\circ} \mathrm{C} / \mathrm{min}$ and following held for $1 \mathrm{~min}$. Triplicate repeats were analyzed, and the obtained data were normalized to the concentrations of external standards and are showed in $\mu \mathrm{M}$ [23].

\subsection{Preparation of L. acidophilus BCRC14079-Fermented Mango Jam Treated with High-Pressure Processing (HPP)}

The L. acidophilus BCRC14079-fermented mango solution was mixed thoroughly with sucrose and pectin. The $\mathrm{pH}$ was maintained at 3.05 using citric acid. The pulp solution was divided into HPP-treatment and heat-treatment groups. For HPP treatment, L. acidophilus BCRC14079-fermented mango pulp was processed at 150, 300, and $500 \mathrm{MPa}$ after being vacuum-packaged in a plastic bag. The processing time and temperature were $20 \mathrm{~min}$ and $25^{\circ} \mathrm{C}$, respectively [24]. For heat treatment, L. acidophilus BCRC14079-fermented mango pulp was mixed with sucrose and pectin and heated by a gas burner at $180^{\circ} \mathrm{C}$. Total soluble solids were monitored during boiling. The solution was continuously stirred and stopped heating when the soluble solids were reached at $65^{\circ}$ Brix. The mixture was then poured into glass beakers to cool under ambient conditions.

\subsection{Texture Profile Analysis (TPA)}

The texture profile analysis (TPA) assay of L. acidophilus BCRC14079-fermented mango jam (60 g; sample height was $24 \mathrm{~cm}$ ) was performed by a texture analyzer (RapidTA ${ }^{\circledR \circledR}$ Texture analyzer, Horn Instruments Co., Ltd., Taoyuan, Taiwan). A knife blade probe (RP40) was used, and the trigger was compressed to $40 \%$ at a $1 \mathrm{~mm} / \mathrm{s}$ speed rate. Triplicate repeats were detected and analyzed by TAdivser software (Version 2.0.1.55, Taoyuan, Taiwan).

\subsection{Color Measurement}

Color analysis of fermented mango jam was determined by using a HunterLab colorimeter (Hunter Associates Laboratory, Inc., Reston, VA, USA). For each sample, triplicate measurements were taken in each shell area, and the average of the four samples was recorded. We determined the lightness component $L^{*}$ (range, $\left.0-100\right)$, and the chromatic components $a^{*}$ (redness/greenness [+/-]) and $b^{*}$ (yellowness/blueness [+/ - ]) [25].

\subsection{Sensory Evaluation}

The appearance, odor, texture, flavor, and overall acceptability of each sample were evaluated by panelists. For a trained sensory panel, panelists were trained to isolate each factor and to focus on each independently of the others for evaluation of the property that is of interest to the researcher. There are 20 panelists in this study, including 9 men and 11 women. Assign a rating to each parameter on a 9-point descriptive hedonic scale, in which 9 is reserved for the highest-quality sample [26]. 


\subsection{Statistical Analysis}

The data were expressed as means $\pm \mathrm{SD}$. The statistical analysis was performed by one-way analysis of variance (ANOVA) to compare among groups through Duncan's multiple-range test (SPSS statistical software package, version 17.0, SPSS, Chicago, IL, USA). Statistic differences with a $p$ value $<0.05$ were considered statistically significant.

\section{Results and Discussion}

\subsection{Properties of L. acidophilus BCRC14079-Fermented Mango}

L. acidophilus, L. plantarum subsp. plantarum, and L. paracasei subsp. paracasei have been used to ferment plant products to improve their antioxidation, anti-inflammation, and lipid metabolism, as well as abilities to prevent acute gastric ulcers, antiatherosclerosis, and antiobesity $[27,28]$. Moreover, some active ingredients, such as $\gamma$-aminobutyric acid (GABA) and angiotensin I converting enzyme inhibitor (ACEI), have been found in lactic acid bacteria-fermented products [29]. Titratable acid and $\mathrm{pH}$ values were determined in lactic acid bacteria L. acidophilus BCRC14079-fermented mango pulp (30\%) after 1, 3, and $5 \mathrm{~d}$ of fermentation. The $\mathrm{pH}$ value decreased significantly $(p<0.05)$, as fermentation progressed from days 3 to 5 (Figure 1A). An increase in titratable acid caused by L. acidophilus BCRC14079 produced lactic acid (Figure 1B). Figure 1C shows the results of L. acidophilus BCRC14079 growth in mango pulp (30\%). The number of L. acidophilus BCRC14079 increased after mango pulp had been fermenting for 3 days, which can exceed approximately $10^{10} \mathrm{CFU} / \mathrm{mL}$. However, the number of L. acidophilus BCRC14079 was lower on day 5, suggesting that the growth of L. acidophilus BCRC14079 in mango pulp as a fermentative material is limited.

(A)

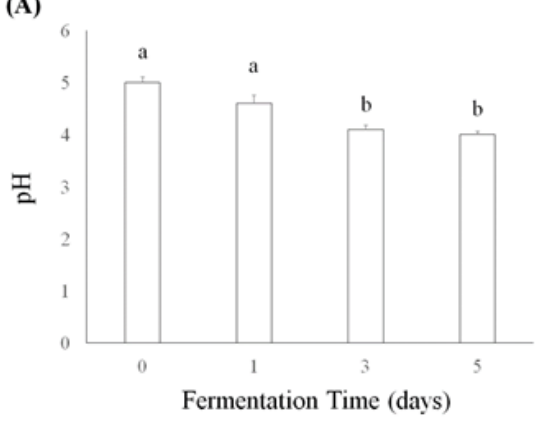

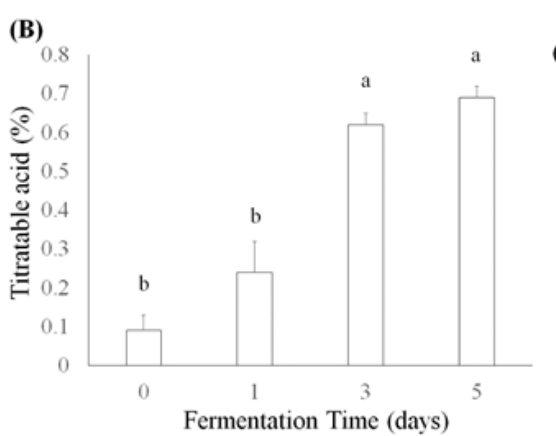

Figure 1. The variations of $(\mathbf{A}) \mathrm{pH},(\mathbf{B})$ titratable acid, and (C) microbial numbers in L. acidophilus BCRC14079-fermented mango after 1,3 , and 5 days, respectively. Data are shown as means $\pm \operatorname{SD}(n=3)$. A significant difference was shown by various letters $(p<0.05)$.

\subsection{Inhibition of the Growth on C. difficile by L. acidophilus BCRC14079-Fermented Mango}

The focus of CDI treatment guidelines is to stop continuing using antibiotics and switching to metronidazole and vancomycin $[30,31]$. However, $C$. difficile develops antibiotic resistance to a number of antibiotics. Therefore, alternative treatment or prevention strategies are needed. The fermented products were centrifuged and divided into L. acidophilus BCRC14079-fermented mango supernatant and precipitate. The inhibition of $C$. difficile growth by L. acidophilus BCRC14079-fermented mango extracts was evaluated.

As shown in Figure 2A, the mango extract, L. acidophilus BCRC14079-fermented mango supernatant and precipitate could inhibit the growth of $C$. difficile dose dependently $(31.25-500 \mu \mathrm{g} / \mathrm{mL})$. The suppressive effect of L. acidophilus BCRC14079-fermented mango supernatant was similar to that of L. acidophilus BCRC14079-fermented mango precipitate ( $24 \mathrm{~h}$ treatment). In addition, a dose of $250 \mu \mathrm{g} / \mathrm{mL}$ was used to evaluate the inhibitory effect in C. difficile treated with mango extracts, L. acidophilus BCRC14079-fermented mango supernatant, and L. acidophilus BCRC14079-fermented mango precipitate for 8, 12, 18, 24, and $36 \mathrm{~h}$. As shown in Figure 2B, the ability of L. acidophilus BCRC14079-fermented mango 
supernatant to inhibit $C$. difficile growth was greater than that of the mango extract and $L$. acidophilus BCRC14079-fermented mango precipitate during 18-36 h.
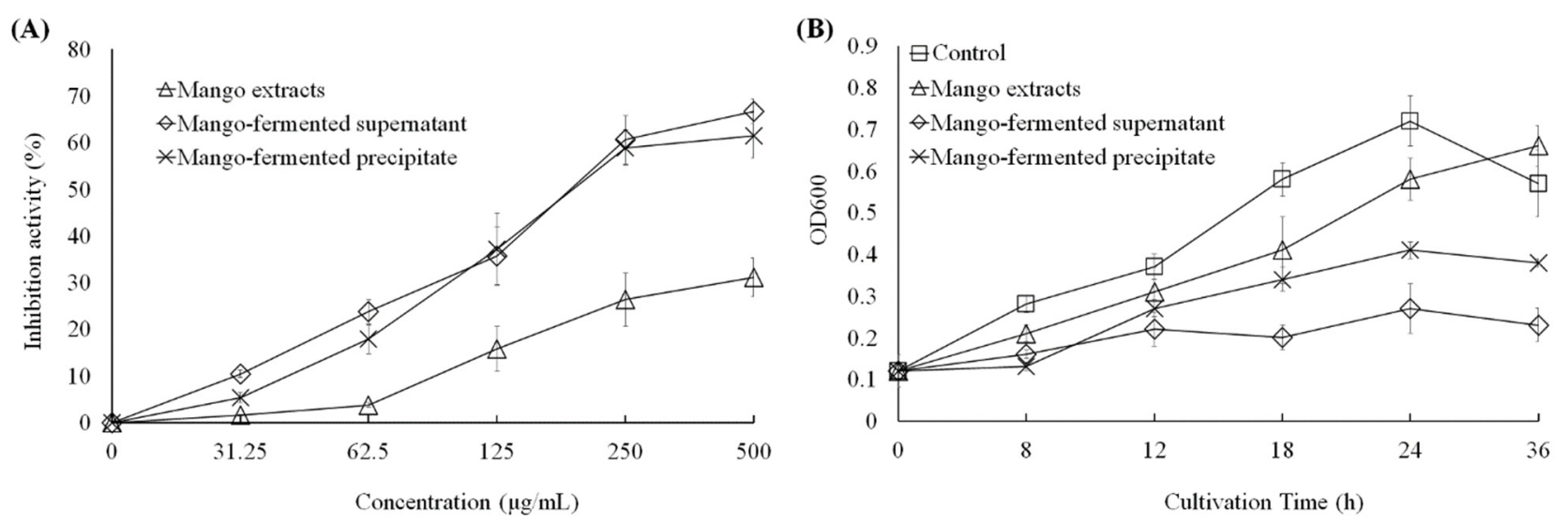

Figure 2. The downregulations of L. acidophilus BCRC14079-fermented mango on the growth of C. difficile in (A) dosagedependent at $24 \mathrm{~h}$ treatment and (B) time-dependent manners at $250 \mu \mathrm{g} / \mathrm{mL}$.

C. difficile belongs to Gram-positive bacillus that produces spores. It is an important pathogenic bacterium in adults and children. C. difficile was first isolated from the intestinal tract of infants and was clinically important when it became one of the main causes of antibiotic-associated diarrhea [30]. Recurrence is an important hallmark of CDI due to the ability of $C$. difficile to produce resistant spores, partly due to the inability to recover the gut microbiota after antibiotic treatment; importantly, $25 \%$ of CDI patients may occur recurrence, and the rate of secondary recurrence can be as high as $40-60 \%[31,32]$.

Cytotoxins toxin $A$ and toxin $B$ are cytotoxic proteins, which are the principal virulence factors of $C$. difficile. Toxins $A$ and B of $C$. difficile are secreted and bound to host receptors, subsequently, entered into the cytoplasm of enterocytes [30,31], which causes intestinal inflammation and surface of the epithelial mucosal disruption [33,34]. In a clinical study, probiotic therapy is also considered in CDI treatment and in antibiotics (vancomycin, metronidazole, and fidaxomicin). Therefore, next-generation probiotics or other probiotic species (such as lactic acid bacteria) are promising novel candidates for the development of CDI adjunct therapy. The protective role of L. casei LBC80R and L. acidophilus CL1285 against CDI has been reported [33]. Moreover, the application of L. reteri products on inhibiting $C$. difficile colonization has been evaluated [35]. We found that $L$. acidophilus BCRC14079-fermented mango can inhibit the growth of $C$. difficile.

In a cell model, toxins A and B have been shown to induce cell necrosis and apoptosis in intestinal epithelial cells $[36,37]$. Therefore, the maintenance of the intestinal barrier is a potential defense against $C$. difficile and reduces the risk of infection. The intestinal mucosa is the first site for the contact between host and pathogen (i.e., virus, bacteria, yeast, protozoa) while infection. Intestinal epithelial cells are able to produce mucin, which can form a mucosal barrier to block tissue represent sits and avoid pathogenic infection.

Apart from mucin, epithelial integrity is associated with intestinal tight junction proteins such as zonula occludens- 1 (ZO-1) and occludin (OCC). These proteins regulate cellular permeability and maintain intestinal barrier functions [38]. We investigated several tight junction proteins involved in intestinal barrier function, including mucin-13, ZO-1, and OCC in Caco-2 cells treated with L. acidophilus BCRC14079-fermented mango. As shown in Figure 3, both L. acidophilus BCRC14079-fermented mango supernatant and precipitate $(250 \mu \mathrm{g} / \mathrm{mL})$ treatment significantly increased the expression of mucin-13, ZO-1, and OCC in Caco-2 cells when compared with mango-extract treatment. 

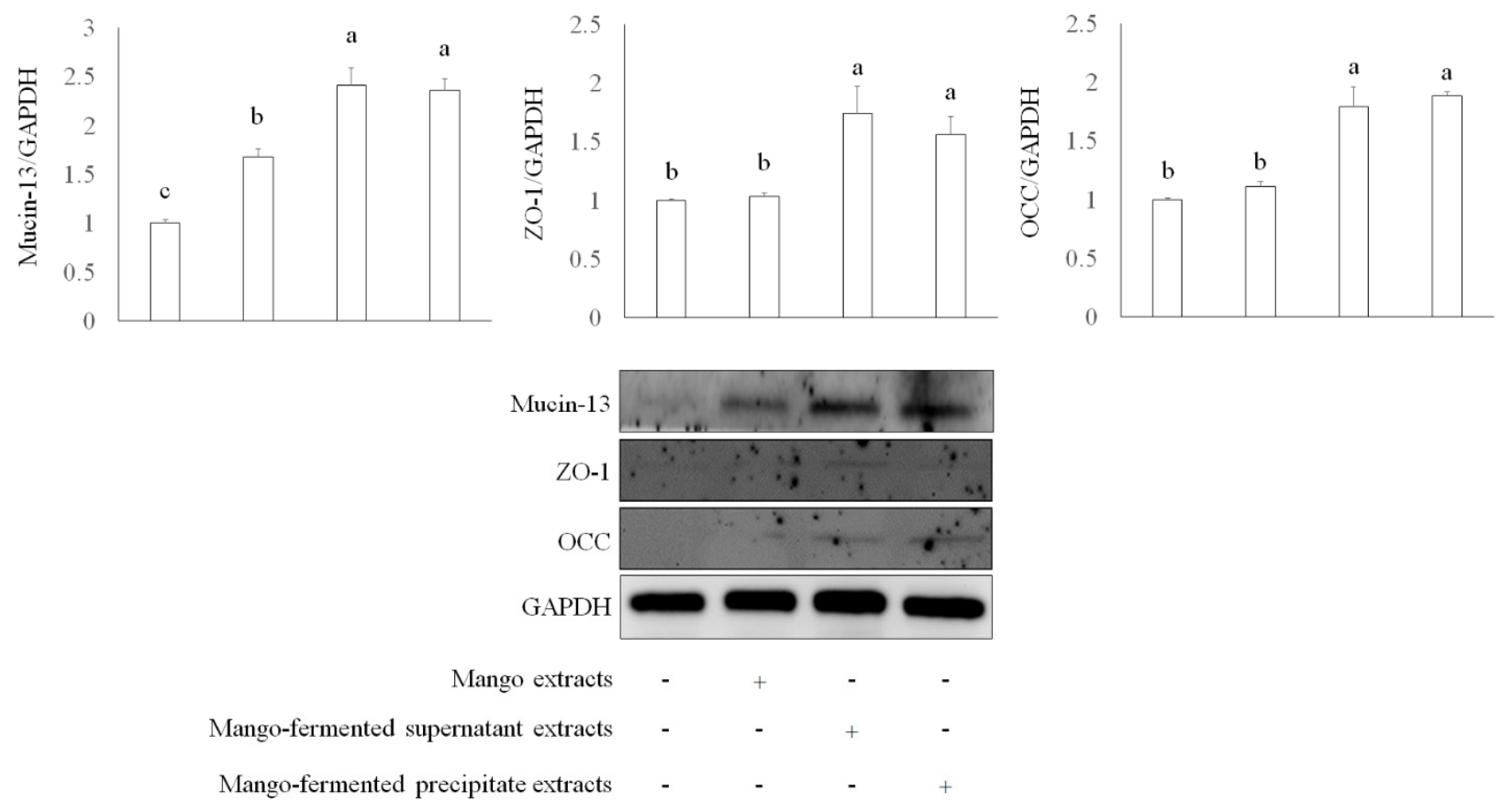

Figure 3. The intestinal protection of L. acidophilus BCRC14079-fermented mango on expressions of mucin-13, ZO-1, and OCC in differential Caco-2 cells. Data are shown as means $\pm \operatorname{SD}(n=3)$. Significant difference was shown by various letters $(p<0.05)$. Symbol + means this sample is added to the group, and symbol - means this sample is not added.

One study has found that $C$. difficile-derived toxin A causes cell apoptosis and reduction of mucosal integrity in Caco-2 cells [39]. Janvilisri et al. (2010) have tried to induce C. difficile infection in Caco-2 cells, and their results showed that the cell viability was decreased after $60 \mathrm{~min}$ infection [40]. We investigated the survival of Caco-2 cells treating with C. difficile for 30, 60, 90, 120, 150, and $180 \mathrm{~min}$. As shown in Figure 4A, cell viability decreased after C. difficile treatment for $120 \mathrm{~min}$. In addition, both L. acidophilus BCRC14079fermented mango supernatant and precipitate extract treatment markedly alleviated the cytotoxic effect of $C$. difficile on Caco-2 cells (Figure 4B). A research study investigates the transcriptomic variation of Caco-2 cells infected with $C$. difficile to understand a framework of host-bacteria interactions. It has been indicated that several biomarkers associated with the epithelial barrier (tight junction proteins) were suppressed by Rho signaling mediation, leading to enterocytes disruption [40,41]. In our study, L. acidophilus BCRC14079-fermented mango has the potential to improve the intestinal barrier and attenuate cell death induced by C. difficile in Caco-2 cells. 

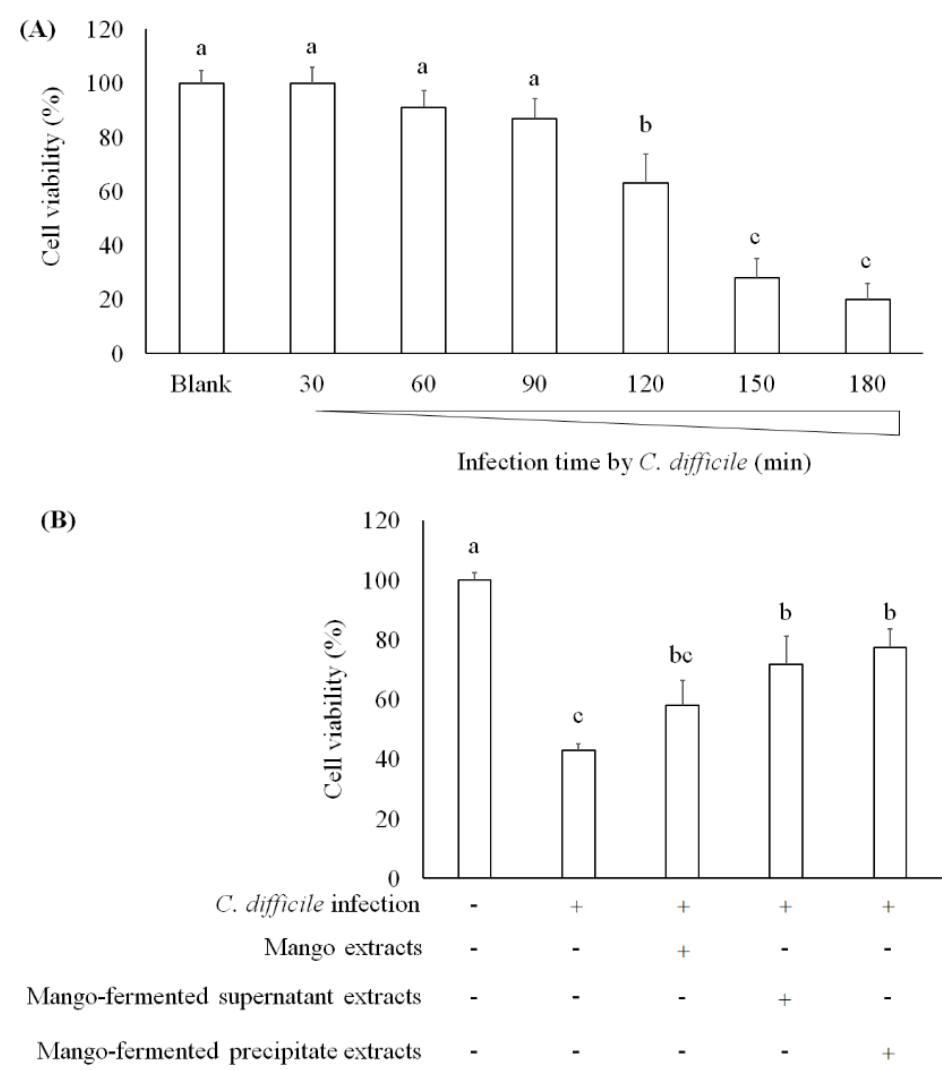

Figure 4. The effect of mango-fermented extracts on the cell viability in Caco-2 cells: (A) cell viability was markedly decreased in cells after $C$. difficile infection for $2 \mathrm{~h}$; (B) the protection of $L$. acidophilus BCRC14079-fermented mango against $C$. difficile infection in Caco-2 cells. Data are shown as means $\pm \mathrm{SD}(n=3)$. Significant difference was shown by various letters $(p<0.05)$. Symbol + means this sample is added to the group, and symbol - means this sample is not added.

\subsection{Regulation of L. acidophilus BCRC14079-Fermented Mango on the Growth of F. prausnitzii}

In this study, we evaluated the effects of L. acidophilus BCRC14079-fermented mango on the growth of F. prausnitzii (Figure 5). Growth of F. prausnitzii was not promoted under culture conditions with the whole mango, L. acidophilus BCRC14079-fermented mango supernatant, or L. acidophilus BCRC14079-fermented mango precipitate extracts. S supplements of the whole mango, L. acidophilus BCRC14079-fermented mango supernatant, or L. acidophilus BCRC14079-fermented mango precipitate extracts in YCFA medium (5\%) significantly increased growth of F. prausnitzii (Figure 5) and production of SCFA (butyrate) (Table 1).

Table 1. The production of short-chain fatty acid production in F. prausnitzii treated with L. acidophilus BCRC14079fermented mango.

\begin{tabular}{cccc}
\hline \multirow{2}{*}{ Short-Chain Fatty Acids } & Acetic Acid & Propionic Acid & Butyric Acid \\
\cline { 2 - 4 } & \multicolumn{3}{c}{ Concentration $(\boldsymbol{\mu M})$} \\
\hline Control & $103.0 \pm 13.2^{\mathrm{c}}$ & $9.5 \pm 1.5$ & $1477.0 \pm 210.6^{\mathrm{b}}$ \\
Mango extracts & $168.1 \pm 18.2^{\mathrm{b}}$ & $11.3 \pm 3.1$ & $1892.0 \pm 141.7^{\mathrm{b}}$ \\
Mango-fermented supernatant extracts & $228.3 \pm 12.5^{\mathrm{a}}$ & $10.6 \pm 2.6$ & $2521.0 \pm 115.3^{\mathrm{a}}$ \\
Mango-fermented precipitate extracts & $241.5 \pm 10.6^{\mathrm{a}}$ & $12.8 \pm 2.2$ & $2263.0 \pm 179.1^{\mathrm{a}}$ \\
\hline
\end{tabular}




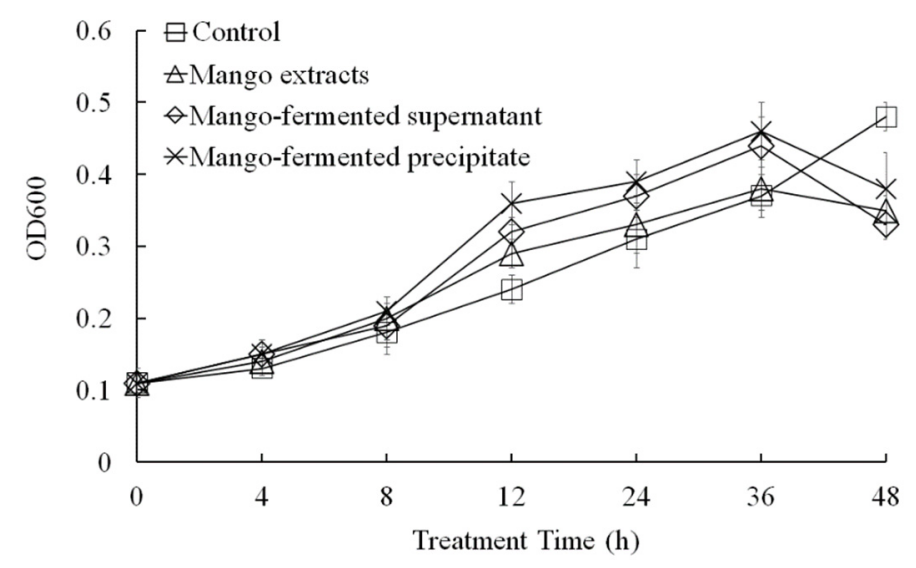

Figure 5. The regulation of L. acidophilus BCRC14079-fermented mango on F. prausnitzii growth. Data are shown as means $\pm \operatorname{SD}(n=3)$. Significant difference was shown by various letters $(p<0.05)$.

The population of F. prausnitzii is potentially regulated by diet and host since it is unable to utilize mucin to be a nutrient, limiting the population within the gut microbiota. However, F. parausnitzii would use mucin metabolites after its degradation; hence, mucin may induce the growth of $F$. prausnitzii while this species is under adequate nutritional condition [42]. Several studies have found that the number of $F$. parausnitzii is increased after prebiotics intervention (e.g., fructooligosaccharides, inulin-type fructans, and raffinose). Evidence suggests that some dietary factors may influence the abundance of $F$. prausnitzii [43]. Several factors including fibers, vitamins, and cofactors (biotin, folate, niacin, and thiamine) are essential nutrients to support the growth of $F$. prausnitzii [44]. Mango is a fiber- and vitamins-riched fruit, it may be a good raw material to elevate the growth of F. prausnitzii.

F. prausnitzii produces short-chain fatty acid butyrate in the colon, which inhibits the growth of $C$. difficile. Moreover, some anti-inflammatory bacteria such as F. prausnitzii and lactic acid bacteria support the innate immune response and minimize bacterial burden and negative effects during antibiotic and C. difficile exposure [45]. Antioxidants-riched lactic acid bacteria (L. rhamnosus R0011) supplements have shown intestinal protection against CDI [46]. Moreover, F. prausnitzii-cultured supernatant showed the ability for inhibiting inflammatory cytokines production in Caco-2 cells [47]. SCFAs promote the expression of tight junction proteins in intestinal cells, including occludin and claudin-5, hence reducing the permeability of the blood-brain barrier (BBB) to avoid the entry of pathogenic bacteria or microbial metabolites into blood [48]. For example, when the concentration of propionate is at least $1 \mu \mathrm{M}$, the permeability of BBB can be protected [49]. Taken together, we consider that $L$. acidophilus BCRC14079-fermented mango can suppress the growth of $C$. difficile, increase the expression of tight junction proteins, and inhibit $C$. difficile by promoting the growth of $F$. prausnitzii and increasing the level of butyrate. These results show that $L$. acidophilus BCRC14079-fermented mango can be developed as a health product to improve the intestinal microenvironment and gut microbiota, and has the potential to be used in the adjuvant treatment of CDI.

\subsection{Development of Innovative Probiotics-Fermented Mango Jam}

Jam, a kind of medium-moisture food product, is prepared by boiling fruit pulp with sugar, acid, pectin, and/or other substances to achieve a suitable and strong consistency to maintain the texture of the fruit. Jam is usually made by mixing fruit and sugar in a ratio of $45 \%: 55 \%$ by weight. Typically, jams are widely consumed for breakfast and incorporated into bakery products and confectionery. With the increasing attention to health and wellness, and the increasing incidence of obesity, metabolic syndrome, and diabetes, the interest in low-calorie foods has also increased [50]. For example, one study produces fiber-fortified fruit jams to enhance the nutrition and texture of jam [51]. 
HPP, also called high hydrostatic pressure processing, is one kind of cold pasteurization technique by which products with the final package are introduced into a vessel and subjected to 100-700 MPa of isostatic pressure that is transmitted by water. L. acidophilus BCRC14079-fermented mango was investigated in this study for developing the fermented jam that contained probiotics. Browning and color loss were found to be higher in the heattreatment group than the HPP-treatment group under all conditions (Table 2). Hardness is defined as the force required to achieve a certain amount of deformation and is a regular parameter to determine the texture of the jam [52]. In sensory analysis, hardness refers to the force required to press food between the teeth during the first bite [53]. Adhesiveness represents the work required to extract the pressure probe from the sample. In sensory analysis, adhesiveness (viscosity) is the work required to overcome the gravity between the food surface and the food contact surface including teeth, tongue, and palate) [52]. Cohesiveness represents the internal resistance of the food structure, which means the ability to combine product ingredients [54].

Table 2. The parameters of L. acidophilus BCRC14079-fermented mango jam by HPP treatment. $L^{*}$ : lightness component (range, 0-100); $a^{*}$ : chromatic component (redness/greenness [+/-]); $b^{*}$ : chromatic component (yellowness/blueness [+/-]).

\begin{tabular}{|c|c|c|c|c|}
\hline \multirow{2}{*}{ Groups } & \multicolumn{3}{|c|}{ HPP Treatment (MPa) } & \multirow{2}{*}{ Heat Treatment } \\
\hline & 150 & 300 & 500 & \\
\hline L. acidophilus BCRC14079-fermented mango solution (\%) & 53.5 & 53.5 & 53.5 & 53.5 \\
\hline $\mathrm{pH}$ & 3.05 & 3.05 & 3.05 & 3.05 \\
\hline Total sugars (\%) & 45 & 45 & 45 & 45 \\
\hline Pectin $(\%)$ & 1.5 & 1.5 & 1.5 & 1.5 \\
\hline$L^{*}$ & 30.76 & 30.53 & 31.81 & 35.49 \\
\hline$a^{*}$ & -3.16 & -3.16 & -3.14 & -2.66 \\
\hline$b^{*}$ & 8.14 & 8.53 & 8.37 & 11.24 \\
\hline
\end{tabular}

We assessed textural characteristics, including hardness, adhesiveness, and cohesiveness (Figure 6). We found that L. acidophilus BCRC14079-fermented mango jam had better hardness, adhesiveness, and cohesiveness than that prepared using mango pulp treated with HPP or heat. Moreover, L. acidophilus BCRC14079-fermented mango jam with HPP treatment at $500 \mathrm{MPa}$ had the highest sensory quality (aroma, taste, color, and overall acceptance) among all groups (Figure 7). Many foods containing lactic acid bacteria can improve human health and inhibit the growth of pathogens; these probiotics are used to develop innovative foods $[55,56]$. A novel type of mango jam was produced in this study, which can enhance the population of next-generation probiotics and inhibit the growth of C. difficile. This jam was fermented using lactic acid bacteria L. acidophilus BCRC14079 and treated with HPP to retain its physicochemical, textural, and rheological properties. 

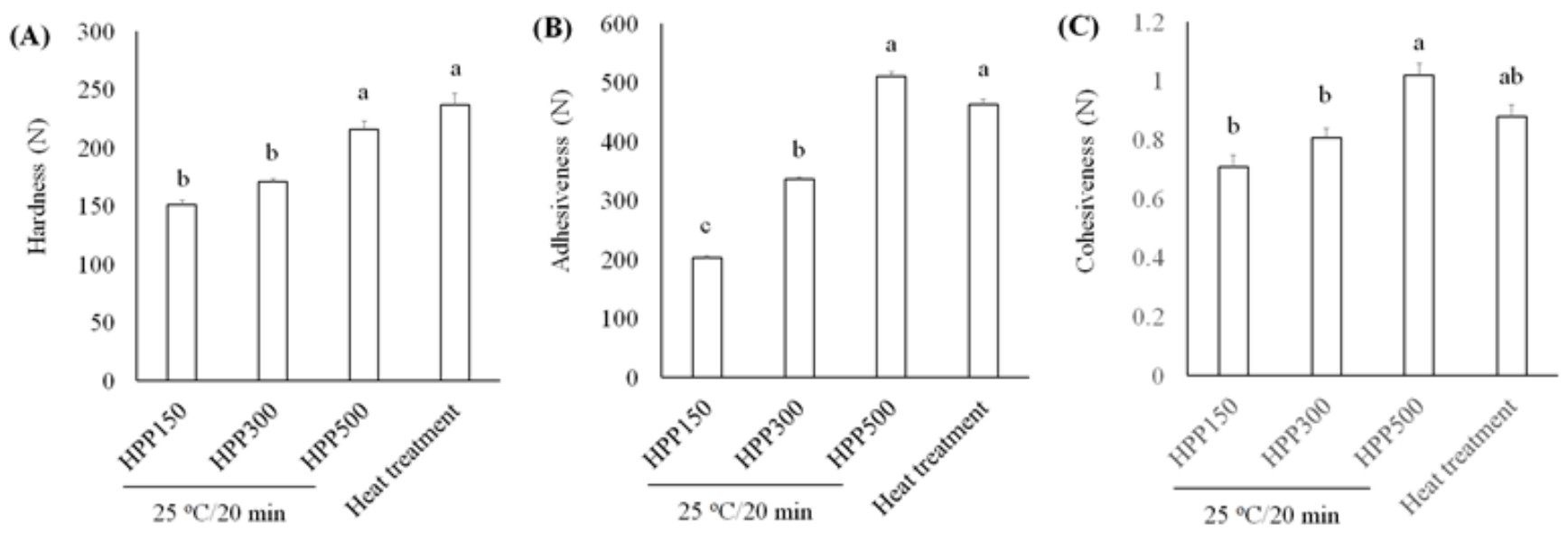

Figure 6. Investigating the textural parameters (A) hardness, (B) adhesiveness, and (C) cohesiveness of L. acidophilus BCRC14079-fermented mango jam by HPP and heat treatment. Data are shown as means \pm SD $(n=3)$. Significant difference was shown by various letters $(p<0.05)$.

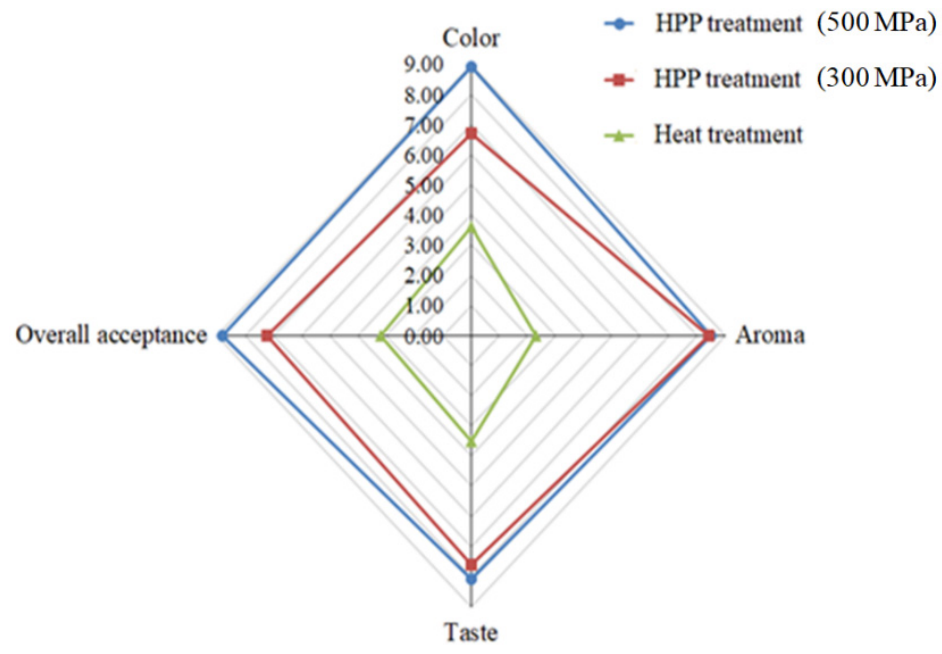

Figure 7. Sensory properties of L. acidophilus BCRC14079-fermented mango jam.

\section{Conclusions}

In this study, L. acidophilus BCRC14079-fermented mango products exhibited beneficial effects by promoting the growth of $F$. prausnitzii and protected intestinal cells against $C$. difficile infection via preventing the cell death of Caco-2 cells. This enteroprotective role of L. acidophilus BCRC14079-fermented mango products is related to improve the gut barrier function through upregulating tight junction proteins expression and mucin secretion. A novel type of mango jam that was fermented by L. acidophilus BCRC14079 and treated with high hydrostatic pressure processing was produced, which had favorable textural characteristics and sensory quality, and had the potential to be developed as an innovative food product for inhibiting the growth of pathogens and improving the human health.

Author Contributions: Conceptualization, B.-H.L. and W.-H.H.; methodology, C.-Y.H. and H.-Y.C.; software, H.-Y.C. and C.-Y.H.; validation, H.-Y.C. and C.-Y.H.; formal analysis, C.-Y.H. and Y.-T.H.; investigation, H.-Y.C. and C.-Y.H.; resources, S.-C.W.; data curation, B.-H.L. and Y.-Z.C.; writingoriginal draft preparation, B.-H.L. and W.-H.H.; writing-review and editing, B.-H.L., W.-H.H. and Y.-Z.C.; visualization, B.-H.L. and Y.-Z.C.; supervision, B.-H.L. and S.-C.W.; project administration, S.-C.W.; funding acquisition, B.-H.L. and S.-C.W. All authors have read and agreed to the published version of the manuscript.

Funding: This research work and subsidiary spending were supported by the Council of Agriculture, Executive Yuan (110AS-14.1.1-ST-a3). 
Institutional Review Board Statement: Not applicable.

Informed Consent Statement: Not applicable.

Data Availability Statement: Not applicable.

Conflicts of Interest: The authors declare no conflict of interest.

\section{References}

1. Asempa, T.E.; Nicolau, D.P. Clostridium difficile infection in the elderly: An update on management. Clin. Interv. Aging 2017, 12, 1799. [CrossRef]

2. Vakili, B.; Fateh, A.; Aghdaei, H.A.; Sotoodehnejadnematalahi, F.; Siadat, S.D. Intestinal microbiota in elderly inpatients with Clostridioides difficile infection. Infect. Drug Resist. 2020, 13, 2723-2731. [CrossRef]

3. Gu, S.; Chen, Y.; Zhang, X.; Lu, H.; Lv, T.; Shen, P.; Lv, L.; Zheng, B.; Jiang, X.; Li, L. Identification of key taxa that favor intestinal colonization of Clostridium difficile in an adult Chinese population. Microbes Infect. 2016, 18, 30-38. [CrossRef] [PubMed]

4. Han, S.H.; Yi, J.; Kim, J.H.; Lee, S.W.; Moon, H.W. Composition of gut microbiota in patients with toxigenic Clostridioides (Clostridium) difficile: Comparison between subgroups according to clinical criteria and toxin gene load. PLoS ONE 2019, 14, e0212626. [CrossRef] [PubMed]

5. Miquel, S.; Martin, R.; Rossi, O.; Bermudez-Humaran, L.G.; Chatel, J.M.; Sokol, H.; Thomas, M.; Wells, J.M.; Langella, P. Faecalibacterium prausnitzii and human intestinal health. Curr. Opin. Microbiol. 2013, 16, 255-261. [CrossRef]

6. Duncan, S.H.; Hold, G.L.; Harmsen, H.J.; Stewart, C.S.; Flint, H.J. Growth requirements and fermentation products of Fusobacterium prausnitzii, and a proposal to reclassify it as Faecalibacterium prausnitzii gen. nov., comb. Nov. Int. J. Syst. Evol. Microbiol. 2002, 52, 2141-2146. [PubMed]

7. Khan, M.T.; Duncan, S.H.; Stams, A.J.; van Dili, J.M.; Flint, H.J.; Harmsen, H.J. The gut anaerobe Faecalibacterium prausnitzii uses an extracellular electron shuttle to grow at oxic-anoxic interphases. ISME J. 2012, 6, 1578-1585. [CrossRef]

8. Wrzosek, L.; Miquel, S.; Noordine, M.L.; Bouet, S.; Chevalier-Curt, M.J.; Robert, V.; Philippe, C.; Bridonneau, C.; Cherbuy, C.; Robbe-Masselot, C.; et al. Bacteroides thetaiotaomicron and Faecalibacterium prausnitzii influence the production of mucus glycans and the development of goblet cells in the colonic epithelium of a gnotobiotic model rodent. BMC Biol. 2013, 11, 61. [CrossRef]

9. Martín, R.; Miquel, S.; Chain, F.; Natividad, J.M.; Jury, J.; Lu, J.; Sokol, H.; Theodorou, V.; Bercik, P.; Verdu, E.F.; et al. Faecalibacterium prausnitzii prevents physiological damages in a chronic low-grade inflammation murine model. BMC Microbiol. 2015, 15, 67. [CrossRef]

10. Zhou, Y.; Xu, H.; Xu, J.; Guo, X.; Zhao, H.; Chen, Y.; Zhou, Y.; Nie, Y. F. prausnitzii and its supernatant increase SCFAs-producing bacteria to restore gut dysbiosis in TNBS-induced colitis. AMB Express 2021, 11, 33. [CrossRef]

11. Rabiei, N.; Badi, S.A.; Marvasti, F.E.; Sattari, T.N.; Vaziri, F.; Siadat, S.D. Induction effects of Faecalibacterium prausnitzii and its extracellular vesicles on toll-like receptor signaling pathway gene expression and cytokine level in human intestinal epithelial cells. Cytokine 2019, 121, 154718. [CrossRef]

12. Duncan, S.H.; Louis, P.; Flint, H.J. Lactate-utilizing bacteria, isolated from human feces, that produce butyrate as a major fermentation product. Appl. Environ. Microbiol. 2004, 70, 5810-5817. [CrossRef]

13. Reddy, L.; Min, J.H.; Wee, Y.J. Production of probiotic mango juice by fermentation of lactic acid bacteria. Korean J. Microbiol. Biotechnol. 2015, 43, 120-125. [CrossRef]

14. Liao, X.Y.; Guo, L.Q.; Ye, Z.W.; Qiu, L.Y.; Gu, F.W.; Lin, J.F. Use of autochthonous lactic acid bacteria starters to ferment mango juice for promoting its probiotic roles. Prep. Biochem. Biotechnol. 2016, 46, 399-405. [CrossRef]

15. Kamassah, A.K.Q.; Saalia, F.K.; Fosu, P.O.; Mensah-Brown, H.; Sinayobye, E.; Tano-Debrah, K. Fermentation capacity of yeasts using mango (Mangiferia indica Linn.) as substrate. Food. Sci. Qual. Manag. 2013, 22, 69-78.

16. Reddy, L.V.; Reddy, O.V.S. Production of ethanol from mango (Mangifera indica L.) fruit juice fermentation. Res. J. Microbiol. 2007, 2, 763-769.

17. Li, X.; Chan, L.J.; Yu, B.; Curran, P.; Liu, S.Q. Fermentation of three varieties of mango juices with a mixture of Saccharomyces cerevisiae and Williopsis saturnus var. mrakii. Int. J. Food Microbiol. 2012, 158, 28-35. [CrossRef] [PubMed]

18. Ordonez-Diaz, J.L.; Moreno-Ortega, A.; Roldan-Guerra, F.J.; Ortiz-Somovilla, V.; Moreno-Rojas, J.M.; Pereira-Caro, G. In vitro gastrointestinal digestion and colonic catabolism of mango (Mangifera indica L.) pulp polyphenols. Foods 2020, 9, 1836. [CrossRef] [PubMed]

19. Hernandez-Maldonado, L.M.; Blancas-Benitez, F.J.; Zamora-Gasga, V.M.; Cardenas-Castro, A.P.; Tovar, J.; Sayago-Ayerdi, S.G. In vitro gastrointestinal digestion and colonic fermentation of high dietary fiber and antioxidant-rich mango (Mangifera indica L.) "Ataulfo"-based fruit bars. Nutrients 2019, 11, 1564. [CrossRef]

20. Gutierrez-Sarmiento, W.; Sayago-Ayerdi, S.G.; Goni, I.; Gutierrez-Miceli, F.A.; Abud-Archila, M.; Rejon-Orantes, J.C.; RinconRosales, R.; Pena-Ocana, B.A.; Ruiz-Valdiviezo, V.M. Changes in intestinal microbiota and predicted metabolic pathways during colonic fermentation of mango (Mangifera indica L.)-based bar indigestible fraction. Nutrients 2020, 12, 683. [CrossRef] [PubMed]

21. van Klinken, B.J.; Oussoren, E.; Weenink, J.J.; Strous, G.J.; Buller, H.A.; Dekker, J.; Einerhand, A.W. The human intestinal cell lines Caco-2 and LS174T as models to study cell-type specific mucin expression. Glycoconj. J. 1996, 13, 757-768. [CrossRef]

22. Altamimi, M.; Abdelhay, O.; Rastall, R.A. Effect of oligosaccharides on the adhesion of gut bacteria to human HT-29 cells. Anaerobe 2016, 39, 136-142. [CrossRef] [PubMed] 
23. Wang, C.Y.; Chen, Y.W.; Tain, Y.L.; Chang, S.K.C.; Huang, L.T.; Hsieh, C.W.; Hou, C.Y. Fast quantification of short-chain fatty acids in rat plasma by gas chromatography. J. Food Sci. 2020, 85, 1932-1938. [CrossRef] [PubMed]

24. Sravani, V.J.; Ravi, N.; Roopa, N.; Kumar, S.; Pandey, A.K.; Chauhan, O.P. Use of high pressure technology for the development of novel jam and its quality evaluation during storage. J. Food Sci. Technol. 2017, 54, 3562-3568. [CrossRef] [PubMed]

25. Papadakis, S.; Abdul-Malek, S.; Kamdem, R.E.; Jam, K.L. A versatile and inexpensive technique for measuring color of foods. Food Technol. 2000, 54, 48-51.

26. Hsu, W.H.; Lai, Y.J.; Wu, S.C. Effects of the anti-microbial peptide pardaxin plus sodium erythorbate dissolved in different gels on the quality of Pacific white shrimp under refrigerated storage. Food Control 2017, 73, 712-719. [CrossRef]

27. Wu, S.C.; Su, Y.S.; Cheng, H.Y. Antioxidant properties of Lactobacillus-fermented and non-fermented Graptopetalum paraguayense E. Walther at different stages of maturity. Food Chem. 2011, 129, 804-809. [CrossRef]

28. Lee, B.H.; Lo, Y.H.; Pan, T.M. Anti-obesity activity of Lactobacillus fermented soy milk products. J. Funct. Foods 2013, 5, 905-913. [CrossRef]

29. Tung, Y.T.; Lee, B.H.; Liu, C.F.; Pan, T.M. Optimization of culture condition for ACEI and GABA production by lactic acid bacteria. J. Food Sci. 2011, 76, M585-M591. [CrossRef]

30. Yang, H.T.; Chen, J.W.; Rathod, J.; Jiang, Y.Z.; Tsai, P.J.; Hung, Y.P.; Ko, W.C.; Paredes-Sabja, D.; Huang, I.H. Lauric acid is an inhibitor of Clostridium difficile growth in vitro and reduces inflammation in a mouse infection model. Front. Microbiol. 2018, 8 , 2635. [CrossRef]

31. Ananthakrishnan, A.N. Clostridium difficile infection: Epidemiology, risk factors and management. Nat. Rev. Gastroenterol. Hepatol. 2011, 8, 17-26. [CrossRef]

32. Johnson, S. Recurrent Clostridium difficile infection: A review of risk factors, treatments, and outcomes. J. Infect. 2009, 58, 403-410. [CrossRef]

33. Johnson, S.; Maziade, P.J.; McFarland, L.V.; Trick, W.; Donskey, C.; Currie, B.; Low, D.E.; Goldstein, E.J.C. Is primary prevention of Clostridium difficile infection possible with specific probiotics? Int. J. Infect. Dis. 2012, 16, e786-e792. [CrossRef]

34. Abt, M.C.; McKenney, P.T.; Pamer, E.G. Clostridium difficile colitis: Pathogenesis and host defense. Nat. Rev. Microbiol. 2016, 14, 609-620. [CrossRef]

35. Spinler, J.; Auchtung, J.; Brown, A.; Boonma, P.; Oezguen, N.; Ross, C.L.; Luna, R.A.; Runge, J.; Versalovic, J.; Peniche, A.; et al. Next-gerneration probiotics targeting Clostridium difficile through precursor-directed antimicrobial biosynthesis. Infect. Immun. 2017, 85, e00303-17. [CrossRef] [PubMed]

36. Mahida, Y.R.; Makh, S.; Hyde, S.; Gray, T.; Borriello, S.P. Effect of Clostridium difficile toxin A on human intestinal epithelial cells: Induction of interleukin 8 production and apoptosis after cell detachment. Gut 1996, 38, 337-347. [CrossRef]

37. Chumbler, N.M.; Farrow, M.A.; Lapierre, L.A.; Franklin, J.L.; Haslam, D.; Goldenring, J.R.; Lacy, D.B. Clostridium difficile toxin B causes epithelial cell necrosis through an autoprocessing-independent mechanism. PLoS Pathog. 2012, 8. [CrossRef]

38. Arbizu, S.; Chew, B.; Mertens-Talcott, S.U.; Noratto, G. Commercial whey products promote intestinal barrier function with glycomaropeptide enhanced activity in downregulating bacterial endotoxin lipopolysaccharides (LPS)-induced inflammation in vitro. Food Funct. 2020, 11, 5842-5852. [CrossRef] [PubMed]

39. Gigli, S.; Seguella, L.; Pesce, M.; Bruzzese, E.; D’Alessandro, A.; Cuomo, R.; Steardo, L.; Sarnelli, G.; Esposito, G. Cannabidiol restores intestinal barrier dysfunction and inhibits the apoptotic process induced by Clostridium difficile toxin A in Caco-2 cells. United Eur. Gastroenterol. J. 2017, 5, 1108-1115. [CrossRef]

40. Janvilisri, T.; Scaria, J.; Chang, Y.F. Transcriptional profiling of Clostridium difficile and Caco-2 cells during infection. J. Infect. Dis. 2010, 202, 282-290. [CrossRef] [PubMed]

41. Pothoulakis, C. Effects of Clostridium difficile toxins on epithelial cell barrier. Ann. N. Y. Acad. Sci. 2000, 915, 347-356. [CrossRef]

42. Lopez-Siles, M.; Duncan, S.H.; Garcia-Gil, L.J.; Martinez-Medina, M. Faecalibacterium prausnitzii: From microbiology to diagnostics and prognostics. ISME J. 2017, 11, 841-852. [CrossRef]

43. Verhoog, S.; Taneri, P.E.; Roa Diaz, Z.M.; Marques-Vidal, P.; Troup, J.P.; Bally, L.; Franco, O.H.; Glisic, M.; Muka, T. Dietary factors and modulation of bacteria strains of Akkermansia muciniphila and Faecalibacterium prausnitzii: A systematic review. Nutrients 2019, 11, 1565. [CrossRef]

44. Heinken, A.; Khan, M.T.; Paglia, G.; Rodionov, D.A.; Harmsen, H.J.; Thiele, I. Functional metabolic map of Faecalibacterium prausnitzii, a beneficial human gut microbe. J. Bacteriol. 2014, 196, 3289-3302. [CrossRef] [PubMed]

45. Roychowdhury, S.; Cadnum, J.; Glueck, B.; Obrenovich, M.; Donskey, C.; Cresci, G.A.M. Faecalibacterium prausnitzii and a prebiotic protect intestinal health in a mouse model of antibiotic and Clostridium difficile exposure. JPEN J. Parenter. Enteral Nutr. 2018, 42, 1156-1167. [CrossRef]

46. Gaisawat, M.B.; Iskandar, M.M.; MacPherson, C.W.; Tompkins, T.A.; Kubow, S. Probiotic supplementation is associated with increased antioxidant capability and copper chelation in C. difficile-infected fecal water. Nutrients 2019, 11, 2007. [CrossRef]

47. Sokol, H.; Pigneur, B.; Watterlot, L.; Lakhdari, O.; Bermudez-Humaran, L.G.; Grtadoux, J.J.; Blugeon, S.; Bridonneau, C.; Furet, J.P.; Corthier, G.; et al. Faecalibacterium prausnitzii is an anti-inflammatory commensal bacterium identified by gut microbiota analysis of Crohn disease patients. Proc. Natl. Acad. Sci. USA 2008, 105, 16731-16736. [CrossRef] [PubMed]

48. Sampson, T.R.; Mazmanian, S.K. Control of brain development, function, and behavior by the microbiome. Cell Host Microb. 2015, 17, 565-576. [CrossRef] [PubMed] 
49. Hoyles, L.; Snelling, T.; Umlai, U.K.; Nicholson, J.K.; Carding, S.R.; Glen, R.C.; McArthur, S. Microbiome-host systems interactions: Protective effects of propionate upon the blood-brain barrier. Microbiome 2018, 6, 55. [CrossRef]

50. Nourmohammadi, A.; Ahmadi, E.; Heshmati, A. Optimization of physicochemical, textural, and rheological properties of sour cherry jam containing stevioside by using response surface methodology. Food Sci. Nutr. 2021, 9, 2483-2496. [CrossRef]

51. Dordevic, D.; Jancikova, S.; Capikova, J.; Tremlová, B.; Kushkevych, I. Chemical and sensory properties of fruit jams affected by bamboo fiber fortification. Biointerface Res. Appl. Chem. 2020, 10, 5247-5251.

52. Mousavi, M.; Heshmati, A.; Garmakhany, A.D.; Vahidinia, A.; Taheri, M. Optimization of the viability of Lactobacillus acidophilus and physico-chemical, textural and sensorial characteristics of flaxseed enriched stirred probiotic yogurt by using response surface methodology. LWT Food Sci. Technol. 2019, 102, 80-88. [CrossRef]

53. Garrido, J.I.; Lozano, J.E.; Genovese, D.B. Effect of formulation variables on rheology, texture, colour, and acceptability of apple jelly: Modelling and optimization. LWT Food Sci. Technol. 2015, 62, 325-332. [CrossRef]

54. Azari-Anpar, M.; Payeinmahali, H.; Daraei Garmakhany, A.; Sadeghi Mahounak, A. Physicochemical, microbial, antioxidant, and sensory properties of probiotic stirred yoghurt enriched with Aloe vera foliar gel. J. Food Proc. Preserv. 2017, 41, e13209. [CrossRef]

55. Martin, I.; Rodriguez, A.; Sanchez-Montero, L.; Padilla, P.; Cordoba, J.J. Effect of the dry-cured fermented sausage "Salchichon" processing with a selected Lactobacillus sakei in Listeria monocytogenes and microbial population. Foods 2021, 10, 856. [CrossRef] [PubMed]

56. Mashitoa, F.M.; Akinola, S.A.; Manhevi, V.E.; Garcia, C.; Remize, F.; Slabbert, R.M.; Sivakumar, D. Influence of fermentation of pasteurized papaya puree with different lactic acid bacterial strains on quality and bioaccessibility of phenolic compounds during in vitro digestion. Foods 2021, 10, 962. [CrossRef] [PubMed] 